\title{
Acta
Biochimica
Polonica
}

Vol. 51 No. 2/2004

$373-378$

QUARTERLY

Review

\section{RNA modulation, repair and remodeling by splice switching oligonucleotides $^{\star}$}

\author{
Ryszard Kole ${ }^{1 凶}$, Tiffany Williams and Lisa Cohen \\ Department of Pharmacology, Medicine, Curriculum in Genetics and Lineberger Comprehensive \\ Cancer Center, University of North Carolina, Chapel Hill, U.S.A.
}

Received: 07 May, 2004; accepted: 20 May, 2004

Key words: RNA splicing; antisense oligonucleotides; genetic disease

Targeting splicing by antisense oligonucleotides allows RNA modifications that are not possible with RNA interference or other antisense techniques that destine the RNA for destruction. By changing the ratio of naturally occurring splice variants the expression of mRNA is modulated. By preventing the use of an aberrant splice site created by a mutation and enforcing re-selection of correct splice sites the RNA is repaired. Antisense induced skipping of the exon that carries a nonsense mutation remodels the mRNA and restores the reading frame of the defective protein. All of the above approaches have clinical applications. Modulation of splice variants is particularly important since close to $60 \%$ of all genes code for alternatively spliced pre-mRNA.

Interest in mRNA as a target for drug therapy has intensified recently with discovery of RNA interference (RNAi) and subsequent attempts to use small interfering RNAs
(siRNAs) as potential therapeutics (Agami, 2002). RNA's appeal is easy to appreciate: the nucleotide sequence provides an opportunity to design sequence-specific and therefore

\footnotetext{
${ }^{\star}$ Presented as invited lecture at the $29^{\text {th }}$ Congress of the Federation of European Biochemical Societies, Warsaw, Poland, 26 June-1 July 2004.

${ }^{凶}$ Editorial correspondence and reprint requests should be addressed to: Ryszard Kole, Lineberger Comprehensive Cancer Center, University of North Carolina, Chapel Hill, NC, 27599, U.S.A.; tel.: (919) 966 1143; fax: (919) 966 9673; e-mail: kole@med.unc.edu

Abbreviations: BMD, Becker muscular dystrophy; DMD, Duchenne muscular dystrophy; EGFP, enhanced green fluorescent protein; FACS, fluorescence-activated cell sorting; PNA, peptide nucleic acid; RNAi, RNA interference; siRNAs, small interfering RNAs; SSOs, splice-switching oligonucleotides; 2'-O-Me, 2'-O-methyl; 2'-O-MOE, 2'-O-methoxyethoxy.
} 
gene-specific drugs. For the most part, research and development of RNA based therapeutics have focused on downregulation of expression of target genes. This review will focus on an oligonucleotide based technology, invented in this laboratory (Dominski \& Kole, 1993; Kole \& Dominski, 1997) that generates modified or repaired mRNAs (see a series of articles in Journal of Clinical Investigation, vol. 112 , issues $3 \& 4$ ), an outcome that is not possible with RNAi and other antisense based techniques (Crooke, 2001). RNA repair and modulation is accomplished by application of antisense oligonucleotides, termed spliceswitching oligonucleotides, (SSOs), which modify alternative splicing patterns of pre-mRNA. The importance of this approach is underscored by the recent realization that the frequency of alternative splicing is higher than previously anticipated, with most studies reporting alternative splice forms in up to $60 \%$ of human genes (Modrek \& Lee, 2002). This mini review presents recent use of SSOs to modulate splicing of targets that illustrate the range of this technology's applications.

\section{RNA MODULATION: Bcl-x AND CANCER}

Bcl-x, like other members of the bcl-2 family of genes is involved in apoptosis. Its two primary splice forms, bcl-xL and bcl-xS, are generated by alternative splicing of bcl-x intron 2 (Cory \& Adams, 2002 and references quoted therein), via the use of a common $3^{\prime}$ splice site and two alternative $5^{\prime}$ splice sites. Bcl-xL, the longer splice variant, is anti-apoptotic. Moreover, high levels of bcl-xL have been correlated with resistance to chemotherapy (Liu et al., 1999). The shorter variant, bcl-xS, which uses a $5^{\prime}$ splice site farther upstream from the $3^{\prime}$ splice site than bcl-xL, has been shown to have anti-apoptotic properties (Minn et al., 1996). SSOs targeted against the bcl-xL $5^{\prime}$ splice site were shown to shift splicing towards production of bcl-xS in the lung epithelial cancer cell line A549 (Taylor et al., 1999). Although the splice shift alone was insufficient to induce apoptosis, it enhanced the apoptotic effects of chemotherapeutics administered with the oligonucleotide. In contrast, prostate cancer PC3 cells, were sensitive to SSO treatment in the absence of anti-cancer drugs (Mercatante et al., 2001). The cell sensitivity was correlated with the level of bcl-x expression or more accurately with the absolute amounts of bcl-xS generated by the anti-bcl-xL SSO. In addition, the SSO treatment sensitized the cells to chemotherapeutics and radiation and interestingly led to cell death in a cell line that was resistant to doxorubicin, a common anti-cancer drug (Mercatante et al., 2002).

Bcl-x is a particularly useful target for SSOs because the two splice variants have opposing functions. Thus, a shift in splicing simultaneously reduces the level of anti-apoptotic Bcl-xL and increases the level of pro-apoptotic Bcl-xL, enhancing the SSOs effect. The results also suggest that expression of possibly thousands of alternatively spliced genes can be manipulated by SSOs either as research tools in investigations of gene function, or possibly as drugs when targeted to disease associated genes, following the example of $b c l-x$ (Mercatante \& Kole, 2000).

\section{RNA REPAIR: $\beta$-THALASSEMIA}

$\beta$-Thalassemia is a blood disease resulting from reduced or absent production of functional $\beta$-globin, a subunit of hemoglobin. Severe cases of thalassemia, if untreated, result in early death. Current treatment consists of frequent transfusions combined with iron chelation therapy. Inability to produce hemoglobin is caused by mutations in the $\beta$-globin gene, affecting various stages of $\beta$-globin biosynthesis. While over 200 mutations lead to disease, several common forms of thalassemia are due to mutations in the $\beta$-globin gene introns that create alternative splice 
sites and lead to aberrant splicing of pre-mRNA. The result is inclusion of the intron fragment, which creates a nonsense codon in the $\beta$-globin coding sequence, preventing translation of the protein (Olivieri, 1999). This laboratory has used splice-switching oligonucleotides to target aberrant splice sites and induce a shift from aberrant to correct splicing, restoring expression of hemoglobin. Sequence-specific correction of splicing was achieved in model cell lines and subsequently by ex vivo treatment of erythroid progenitors cells from thalassemia patients (reviewed in Sazani et al., 2002a). In these studies, the SSOs were delivered by cationic lipid delivery agents or by temporary, mechanical damage to cell membranes (Lacerra et al., 2000). Free uptake of SSOs by the cultured erythroid cells was also accomplished using oligonucleotides with a neutral, morpholino backbone. High levels of correct RNA and hemoglobin expression were achieved after several days of treatment (Suwanmanee et al., 2002a; 2002b).

Like most other pharmacological agents, SSOs effects are relatively short term due to their degradation and excretion. Thus, the possibility of long-term repair of $\beta$-globin pre-mRNA has also been investigated. The sequence antisense to the aberrant splice sites in $\beta$-globin pre-mRNA was cloned into a U7 snRNA gene, and the modified anti- $\beta$-globin U7 snRNA expressed from its own promoter served as a means to deliver antisense sequences to erythroid cell nuclei. Previous work relied on transfection of appropriate plasmids. Recently the modified U7 gene was incorporated into lentiviral vectors (Vacek et al., 2003). Treatment of cells, both model cell lines and thalassemic patients erythroid progenitor, resulted in significant upregulation of $\beta$-globin mRNA and functional protein expression. Although the level of expression was not as high as in the SSO treated cells, the effects were permanent in the cell lines and lasted as long as the primary erythroid cells could be maintained in culture (Vacek et al., 2003). Antisense RNA delivery via lentiviral vectors is especially appealing in chronic diseases such as $\beta$-thalassemia that require lifelong correction of splicing.

One advantage of RNA repair, especially for the gene that is as tightly developmentally controlled as $\beta$-globin is that the target gene is expressed in its natural environment and therefore cannot be over- or inappropriately expressed. As mentioned in the introduction, RNA repair allows up-regulation or re-expression of a defective gene, a result that cannot be achieved by RNAi or standard antisense approaches.

\section{RNA REMODELING: DUCHENNE MUSCULAR DYSTROPHY}

Duchenne muscular dystrophy (DMD) is an $\mathrm{X}$-linked disorder resulting from nonsense or frameshift point mutations in the dystrophin gene that prevent translation of functional dystrophin protein (Matsuo, 1996). Inability to produce dystrophin leads to progressive muscle wasting and early death. Interestingly, large internal deletions, preserve the translational reading frame, resulting in shortened but partially functional dystrophin, lead to a milder form of the disorder, Becker muscular dystrophy (BMD). Several groups have investigated antisense therapy in $m d x$ mouse models of DMD, in which a nonsense mutation in exon 23 disrupts the reading frame of the dystrophin gene. In earlier work SSOs were targeted to $5^{\prime}$ and $3^{\prime}$ splice sites to induce skipping of exon 23 , thus resulting in a shortened but in-frame dystrophin protein: in essence, antisense therapy was designed to create partially functional BMD-like protein, reducing the DMD phenotype (Wilton et al., 1999). More recently, antisense oligonucleotides injected into limbs of $m d x$ mice with nonsense dystrophin mutations were shown to partially restore dystrophin production and induce dystrophin protein localization in the muscle sarcolemma. Importantly, the 
mice regained partial function in the injected muscle (Gebski et al., 2003; Lu et al., 2003).

Targeting of DMD presents an interesting and novel use of SSO technology. Although the dystrophin gene is not alternatively spliced, and DMD does not arise from splicing mutations, SSOs treatment can be used to repair the RNA and restore the function of a defective gene.

\section{ANTISENSE DEVELOPMENT: POSITIVE READ-OUT ASSAY}

Although antisense oligonucleotides are getting close to being accepted as therapeutics and are undergoing numerous clinical trials (http://www.clinicaltrials.gov/) their delivery and cellular uptake still need improvement. An assay that provides clear, sequence specific and sensitive read-out would be very useful in further investigations of the improved oligonucleotides. Modification of splicing by SSOs, which results in generation of a new splice variant on a null or low background, provides such an assay. This assay was devised and exploited in this laboratory to analyze in cell culture and in vivo the antisense effects of several novel oligonucleotide chemistries.

The assay utilizes an enhanced green fluorescent protein (EGFP) the coding sequence of which is interrupted by a defective intron from human $\beta$-globin gene. The intron carries a thalassemic mutation that creates an aberrant $5^{\prime}$ splice site and activates an additional $3^{\prime}$ splice site upstream. The resultant aberrant splicing prevents production of correct EGFP mRNA and protein (Sazani et al., 2001). For in vitro and in vivo testing, this construct was either stably transfected into HeLa cells or expressed in a transgenic mouse model. In the absence of oligonucleotide treatment virtually no EGFP mRNA was present and very little or no background fluorescence was detected in cultured cells or mouse tissues. These systems test sequence- specific antisense activity; the generated fluorescence is directly proportional to the effectiveness of the antisense molecules in splice shifting. A positive readout confirms that the antisense molecule was able to cross the plasma and nuclear membranes, bind to its target pre-mRNA in the nucleus in a sequence specific manner and interfere with the normal functioning of the spliceosome. The results can be quantified at the mRNA or protein level, by fluorescence-activated cell sorting (FACS) analysis of cultured cells or microscopy of sectioned mouse tissue. The assay allows comparison of effectiveness of oligonucleotide analog chemistries, delivery agents and different delivery approaches.

Using this assay, antisense properties of peptide nucleic acid (PNA), morpholino, 2'-Omethoxyethoxy (2'-O-MOE) and $2^{\prime}$-O-methyl ( $\left.2^{\prime}-\mathrm{O}-\mathrm{Me}\right)$ were investigated. Interestingly, with 'free uptake' of the oligonucleotides into cultured HeLa cells, with no special delivery methods or agents, antisense efficiency seemed to be related to a net backbone charge. The neutral PNA and morpholino analogs performed better than their negative counterparts (2'-O-MOE and 2'-O-Me). The addition of four lysine residues to PNA analogs increased their efficacy presumably due to a positive charge conferred by the basic amino acids (Sazani et al., 2001).

Consistent with in vitro cell line data, the PNA-4-lysine chemistry out-performed all other oligonucleotides tested in vivo, exhibiting significant fluorescence in the liver, kidney, heart and lung tissues of the EGFP mouse. Unexpectedly, 2'-O-MOE treated animals also showed intense response to treatment with detectable fluorescence in several tissues while the neutral morpholino oligonucleotide analog showed little response in all tissues tested (Sazani et al., 2002b). Lack of morpholino effects is likely a consequence of rapid renal clearance of such molecules (Agrawal et al., 1995). Recently the EGFP-based splicing assay was also used for cell culture testing of oligonucleotide based 
modifications that increased binding of these compounds to their target. No effect on splice shifting was observed (Sazani et al., 2003). An earlier version of the assay, based on luciferase read-out (Kang et al., 1998) was also used to study morpholino oligonucleotides conjugated to peptides some of which were found to improve cellular and nuclear uptake of the conjugates (Moulton et al., 2003).

\section{R E F E R E N C E S}

Agami R. (2002) RNAi and related mechanisms and their potential use for therapy. Curr Opin Chem Biol.; 6: 829-34.

Agrawal S, Temsamani J, Galbraith W, Tang J. (1995) Pharmacokinetics of antisense oligonucleotides. Clin Pharmacokinet.; 28: 7-16.

Boise LH, Gonzalez-Garcia M, Postema CE, Ding L, Lindsten T, Turka LA, Mao X, Nunez G, Thompson CB. (1993) bcl-x, a $b c l-2$-related gene that functions as a dominant regulator of apoptotic cell death. Cell.; 74: $597-608$.

Cheng TC, Orkin SH, Antonarakis SE, Potter MJ, Sexton JP, Markham AF, Giardina PJ, Li A, Kazazian HH Jr. (1984) $\beta$-Thalassemia in Chinese: use of in vivo RNA analysis and oligonucleotide hybridization in systematic characterization of molecular defects. Proc Natl Acad Sci USA.; 81: 2821-5.

Cory S, Adams JM. (2002) The Bcl2 family: regulators of the cellular life-or-death switch. Nat Rev Cancer.; 2: 647-56.

Crooke S. (2001) Basic principles of antisense technology. In Antisense drug technology: principles, strategies and applications. pp 1-28. Marcel Dekker, New York, NY.

Dominski Z, Kole R. (1993) Restoration of correct splicing in thalassemic pre-mRNA by antisense oligonucleotides. Proc Natl Acad Sci USA.; 90: 8673-7.

Gebski BL, Mann CJ, Fletcher S, Wilton SD. (2003) Morpholino antisense oligonucleotide induced dystrophin exon 23 skipping in $m d x$ mouse muscle. Hum Mol Genet.; 12: 1801-11.

Kang SH, Cho MJ, Kole R. (1998) Up-regulation of luciferase gene expression with antisense oligonucleotides: implications and applications in functional assay development. Biochemistry.; 37: 6235-9.

Kole R, Dominski Z. (1997) Antisense oligonucleotides which combat aberrant splicing and methods of using the same. US Patent 5,627,274.

Lacerra G, Sierakowska H, Carestia C, Fucharoen S, Summerton J, Weller D, Kole R. (2000) Restoration of hemoglobin A synthesis in erythroid cells from peripheral blood of thalassemic patients. Proc Natl Acad Sci USA.; 97: 9591-6.

Liu R, Page C, Beidler DR, Wicha MS, Nunez G. (1999) Overexpression of Bcl-x(L) promotes chemotherapy resistance of mammary tumors in a syngeneic mouse model. Am $J$ Pathol.; 155: 1861-7.

Lu QL, Mann CJ, Lou F, Bou-Gharios G, Morris GE, Xue SA, Fletcher S, Partridge TA, Wilton SD. (2003) Functional amounts of dystrophin produced by skipping the mutated exon in the $m d x$ dystrophic mouse. Nat Med.; 9: 1009-14.

Mann CJ, Honeyman K, Cheng AJ, Ly T, Lloyd F, Fletcher S, Morgan JE, Partridge TA, Wilton SD. (2001) Antisense-induced exon skipping and synthesis of dystrophin in the $m d x$ mouse. Proc Natl Acad Sci USA.; 98: 42-7.

Matsuo M. (1996) Duchenne/Becker muscular dystrophy: from molecular diagnosis to gene therapy. Brain Dev.; 18: 167-72.

Mercatante D, Kole R. (2000) Modification of alternative splicing pathways as a potential approach to chemotherapy. Pharmacol Ther.; 85: $237-43$.

Mercatante DR, Mohler JL, Kole R. (2002) Cellular response to an antisense-mediated shift of Bcl-x pre-mRNA splicing and antineoplastic agents. J Biol Chem.; 277: 49374-82.

Mercatante DR, Bortner CD, Cidlowski JA, Kole R. (2001) Modification of alternative 
splicing of Bcl-x pre-mRNA in prostate and breast cancer cells. Analysis of apoptosis and cell death. J Biol Chem.; 276: 16411-7.

Minn AJ, Boise LH, Thompson CB. (1996) Bcl-x(S) antagonizes the protective effects of Bcl-x(L). J Biol Chem.; 271: 6306-12.

Modrek B, Lee C. (2002) A genomic view of alternative splicing. Nat Genet.; 30: 13-9.

Moulton HM, Hase MC, Smith KM, Iversen PL. (2003) HIV Tat peptide enhances cellular delivery of antisense morpholino oligomers. Antisense Nucleic Acid Drug Dev.; 13: 31-43.

Olivieri NF. (1999) The $\beta$-thalassemias. $N$ Engl J Med.; 341: 99-109.

Sazani P, Kang SH, Maier MA, Wei C, Dillman J, Summerton J, Manoharan M, Kole R. (2001) Nuclear antisense effects of neutral, anionic and cationic oligonucleotide analogs. Nucleic Acids Res.; 29: 3965-74.

Sazani P, Vacek MM, Kole R. (2002a) Short-term and long-term modulation of gene expression by antisense therapeutics. Curr Opin Biotechnol.; 13: 468-72.

Sazani P, Gemignani F, Kang SH, Maier MA, Manoharan M, Persmark M, Bortner D, Kole R. (2002b) Systemically delivered antisense oligomers upregulate gene expression in mouse tissues. Nat Biotechnol.; 20: 1228-33.

Sazani P, Astriab-Fischer A, Kole R. (2003) Effects of base modifications on antisense properties of 2'-O-methoxyethyl and PNA oligonucleotides. Antisense Nucleic Acid Drug Dev.; 13: 119-28.

Suwanmanee T, Sierakowska H, Fucharoen S, Kole R. (2002a) Repair of a splicing defect in erythroid cells from patients with $\beta$-thalassemia/HbE disorder. Mol Ther; 6: 718-26.

Suwanmanee T, Sierakowska H, Lacerra G, Svasti S, Kirby S, Walsh C, Fucharoen S, Kole R. (2002b) Restoration of human $\beta$-globin gene expression in murine and human IVS2-654 thalassemic erythroid cells by free uptake of antisense oligonucleotides. $\mathrm{Mol}$ Pharmacol.; 62: 545-53.

Taylor JK, Zhang QQ, Wyatt JR, Dean NM. (1999) Induction of endogenous Bcl-xS through the control of Bcl-x pre-mRNA splicing by antisense oligonucleotides. Nat Biotechnol.; 17: 1097-100.

Vacek MM, Ma H, Gemignani F, Lacerra G, Kafri T, Kole R. (2003) High-level expression of hemoglobin $\mathrm{A}$ in human thalassemic erythroid progenitor cells following lentiviral vector delivery of an antisense snRNA. Blood; 101: 104-11.

Wilton SD, Lloyd F, Carville K, Fletcher S, Honeyman K, Agrawal S, Kole R. (1999) Specific removal of the nonsense mutation from the $m d x$ dystrophin mRNA using antisense oligonucleotides. Neuromuscul Disord.; 9: 330-8. 